\title{
BMJ Open Developing a classification system for haemoglobin management in patients with end-stage renal disease on haemodialysis: a secondary data analysis
}

Tibor Kesztyüs, ${ }^{1,2}$ Ulrich Simonsmeier, ${ }^{3}$ Dorothea Kesztyüs ${ }^{4}$

To cite: Kesztyüs T, Simonsmeier U, Kesztyüs D. Developing a classification system for haemoglobin management in patients with end-stage renal disease on haemodialysis: a secondary data analysis. BMJ Open 2017;7:e017423. doi:10.1136/ bmjopen-2017-017423

- Prepublication history for this paper is available online. To view these files please visit the journal online (http://dx.doi org/10.1136/bmjopen-2017017423).

Received 22 April 2017 Revised 6 September 2017 Accepted 25 September 2017

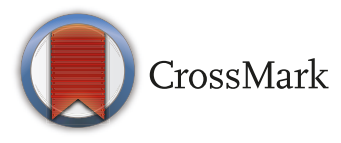

${ }^{1}$ Department of Computer Science, Ulm University of Applied Sciences, Ulm, BadenWürttemberg, Germany ${ }^{2}$ Institute of Medical Systems Biology, Ulm University, Ulm, Baden-Württemberg, Germany ${ }^{3}$ Cybernius Medical Ltd, St. Albert, Alberta, Canada ${ }^{4}$ Institute of General Practice, Ulm University, Ulm, BadenWürttemberg, Germany

Correspondence to Dr Dorothea Kesztyüs; dorothea.kesztyues@uni-ulm.de

\section{ABSTRACT}

Background Ongoing discussion on anaemia management and target haemoglobin $(\mathrm{Hb})$ levels in patients on haemodialysis with erythropoietin treatment require a systematic approach in evaluating current practice. Aim of the present study was to develop a new classification system to easily monitor $\mathrm{Hb}$ trajectories and categorise patients on haemodialysis.

Methods Routine data from five dialysis centres in the USA collected between 2010 and 2016. Data were anonymised and only those from patients with fortnightly $\mathrm{Hb}$ values were included in the analysis. Entries on blood parameters and medication were standardised to achieve overall comparability. Data from each patient was grouped in periods of 120 days. Hb values above or below the target level of $10-12 \mathrm{~g} / \mathrm{dL}$ were counted for each period. Periods were then assigned to $\mathrm{Hb}$-classes according to the number of $\mathrm{Hb}$ values out of range per period: $\mathrm{Hb}$-class I with $0-2, \mathrm{Hb}$-class || for $3-5$ and $\mathrm{Hb}$-class III for $\geq 6$ values out of range.

Results Records from 3349 patients with fortnightly $\mathrm{Hb}$ values, information on haemodialysis data, laboratory parameters correlated to red blood cells and data on medication with erythropoiesis-stimulating agents (ESAs) were available. Patients were $64.4 \pm 15.9$ years old; $55.0 \%$ were men. Statistical analysis revealed significant differences between $\mathrm{Hb}$-classes in all of the examined parameters, except erythrocytes mean corpuscular volume and $\mathrm{C}$ reactive protein above the threshold, with more critical values in higher $\mathrm{Hb}$-classes. The usage of ESAs showed a mean difference between $\mathrm{Hb}$-class III and $\mathrm{Hb}$-class I of 6.4 units/ day and kilogram body weight in a 120-day period. Conclusion Our classification system allows an easily achievable overview of the patients' responsiveness and performance of $\mathrm{Hb}$ management. Integrated into a disease management programme or continuous quality improvement, the classification delivers an instant appraisal without complex statistical or mathematical processing.

\section{INTRODUCTION}

Chronic kidney disease (CKD) contributes to the globally growing burden of non-communicable diseases, which represent the largest cause of death worldwide. ${ }^{1}$ As the
Strengths and limitations of this study

- This study provides a data analysis of 8899 patient years with fortnightly haemoglobin values.

- The proposed classification scheme can be applied easily and facilitates comparisons in any direction.

- A large number of data sets had to be omitted because of missing information which could have led to a positive selection.

US Centers for Disease Control and Prevention announced, about one out of two adults aged between 30 and 64 is expected to develop CKD in their lifetime. ${ }^{2}$ In 2013, there were more than 660000 prevalent cases of end-stage renal disease (ESRD) in the US population, $63.7 \%$ of them receiving haemodialysis therapy. ${ }^{3}$ Prevalence rates of CKD in the adult population in Europe vary considerably between countries, and are highest in north-east Germany at $17.3 \% .^{4}$ ESRD is growing in the European Union, but despite a similar prevalence of CKD, the incidence rates of ESRD were three times higher in the USA in comparison to Norway. ${ }^{5}$ Due to a strong link between obesity and CKD, alongside improved survival and a lower likelihood for transplantation, an increase in the ESRD population, at least in the USA, is expected. ${ }^{6}$

Deficiency in the renal erythropoietin production in patients with CKD leads to anaemia and, subsequently, to severe restrictions to health and quality of life. In the late 1980 s, recombinant human erythropoietin (rHuEpo) was tested in clinical trials for its safety and efficacy for patients on haemodialysis, aiming at a correction of renal anaemia. ${ }^{7}$ Meanwhile, anaemia treatment in ESRD with erythropoiesis-stimulating agents (ESAs) is routinely applied, and the remaining discussion revolves more around the question 


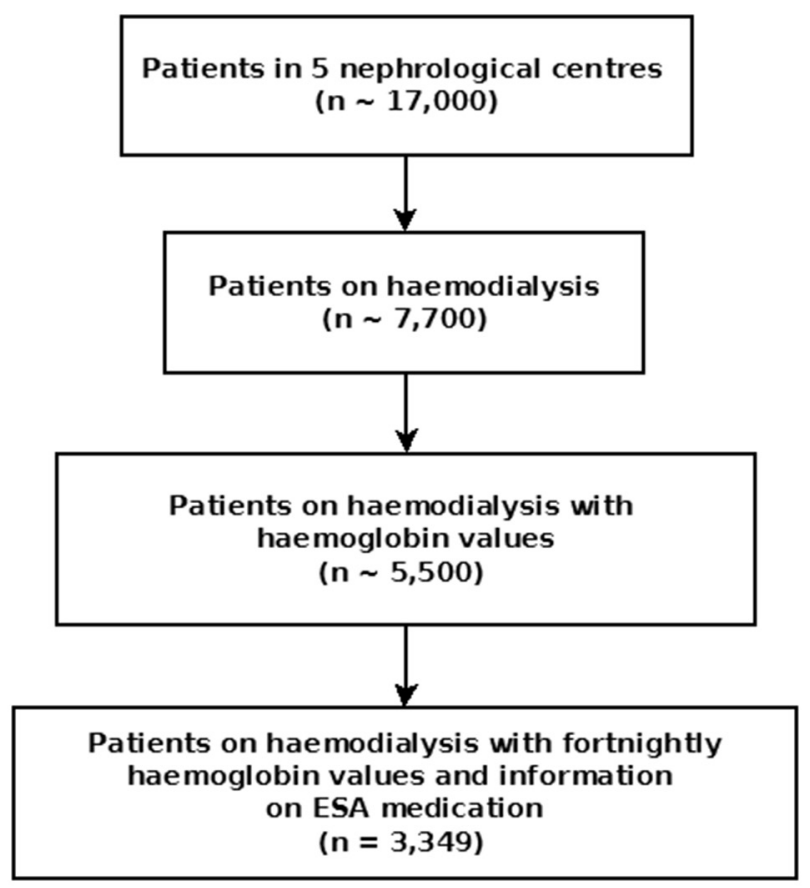

Figure 1 Flow chart of record sets of patients included in the secondary data analysis. ESA, erythropoiesis-stimulating agent; Hb, haemoglobin.

of early or delayed administration rather $^{8}$ than the use itself. Research studies to distinguish the quality between different types of available ESA formulations in terms of efficacy and safety are currently scarce and offer insufficient evidence, so that drug costs, availability and preferences for dosing frequency might serve as decision-making tools. ${ }^{9}$

The introduction of ESA significantly improved anaemia therapy in patients with CKD by relieving symptoms and avoiding complications associated with blood transfusion. ${ }^{8}$ On the other hand, fully correcting anaemia with ESAs is under suspicion of being associated with increased cardiovascular mortality rates and non-cardiac fatal events. ${ }^{8}$ Moreover, in contrast to predominantly stable levels in healthy individuals, a cyclic up and down of haemoglobin $(\mathrm{Hb})$ values under rHuEpo therapy is often observed. ${ }^{10}$ This $\mathrm{Hb}$ cycling is associated with frequent changes in rHuEpo dosing, iron treatment methods and hospitalisation. ${ }^{10}$ A related problem is the frequently reported variability of $\mathrm{Hb}$ levels in patients with ESRD with haemodialysis, which is independently associated with higher mortality. ${ }^{11}$

Currently, recommended $\mathrm{Hb}$ target levels for ESA anaemia treatment in CKD in the USA are in the range of $11.0-12.0 \mathrm{~g} / \mathrm{dL}$ and should not be greater than $13.0 \mathrm{~g} /$ $\mathrm{dL}$, whereas $\mathrm{Hb}$ levels $>13.0 \mathrm{~g} / \mathrm{dL}$, within the physiologically normal range for healthy individuals, were assumed to be associated with a higher risk of mortality for patients with CKD. ${ }^{12}$ However, a Cochrane review of 22 trials did not find a significant difference in the risk of death for low $(<12 \mathrm{~g} / \mathrm{dL})$ versus higher $\mathrm{Hb}$ targets $(>13.3 \mathrm{~g} / \mathrm{dL}){ }^{13}$ In their clinical practice guidelines, the Kidney Disease
Improving Global Outcomes (KDIGO) Work Group suggests ESAs should not be used to maintain $\mathrm{Hb}$ concentration above $11.5 \mathrm{~g} / \mathrm{dL}$ in adult patients with CKD, but recommends an individualisation of therapy for some patients who may have improvements in quality of life with higher $\mathrm{Hb}$ concentrations. ${ }^{14}$

Data from the Dialysis Outcomes and Practice Patterns Study Practice Monitor indicate that in the USA, since October 2013, the percentage of patients with $\mathrm{Hb}$ above $12 \mathrm{~g} / \mathrm{dL}$ was $14 \%-15 \%$ while those with $\mathrm{Hb}$ below $10 \mathrm{~g} /$ dL was at $18 \%-20 \%^{15}$; in sum these are $32 \%-45 \%$ of patients with $\mathrm{Hb}$ levels outside the recommended range. Moreover, current evaluations still discuss high variability and continued cycling in longitudinal $\mathrm{Hb}$ trajectories that might be improved. ${ }^{1617}$ A tool to classify and monitor the amount of $\mathrm{Hb}$ data out of range could be useful in many ways: to describe and compare individual patients as well as patient collectives; as a basis for further considerations of, for example, performance of $\mathrm{Hb}$ management and finally as an integrative part in a clinical decision support tool. Hence, in this article, we will introduce a new, descriptive classification system for the monitoring of $\mathrm{Hb}$ trajectories in patients using haemodialysis treated with ESAs.

\section{METHODS AND DATA}

The reporting guidelines of the STrengthening the Reporting of OBservational studies in Epidemiology statement were used in writing this manuscript.

\section{Participating centres}

Secondary data analysis was conducted with data from five nephrological centres in the USA. All data were collected between 2010 and 2016 in participating centres within the medical record system, cyberREN (Cybernius Medical, St Albert, AB, Canada), which is used in over 20 dialysis centres across the USA. Cybernius Medical selected five centres and the authorised persons in these centres gave written informed consent to a secondary data analysis of anonymised data. In total, the original data set consisted of records of 17000 patients. From these, only patients on haemodialysis who were treated with ESAs were taken into account. According to the database $60 \%$ of patients on haemodialysis were treated with ESAs while for $40 \%$ of patients no information on ESA use was given. Those patients presumably either did not receive ESA treatment or respective data were not documented. To fulfil the requirements for the analyses with regard to erythropoietic outcomes, only records with information on fortnightly $\mathrm{Hb}$ values, haemodialysis data, laboratory parameters correlated to red blood cells and data on medication with rHuEpo or darbepoetin were taken into account. These requirements were fulfilled by the records of 3349 patients. Figure 1 illustrates the selection of patient records.

\section{Data management}

Despite the fact that all centres were using the same medical record system, they all had their own databases 


\begin{tabular}{|c|c|c|c|}
\hline Parameter & Abbreviation & Unit & Threshold \\
\hline \multicolumn{4}{|c|}{ Parameters correlated to red blood cells } \\
\hline Haemoglobin & $\mathrm{Hb}$ & $\mathrm{g} / \mathrm{dL}$ & \\
\hline Haematocrit & Hct & $\%$ & \\
\hline $\begin{array}{l}\text { Mean corpuscular } \\
\text { volume }\end{array}$ & MCV & $\mathrm{fL}$ & \\
\hline $\begin{array}{l}\text { Mean corpuscular } \\
\text { haemoglobin }\end{array}$ & $\mathrm{MCH}$ & $\mathrm{pg}$ & \\
\hline $\begin{array}{l}\text { Mean corpuscular } \\
\text { haemoglobin } \\
\text { concentration }\end{array}$ & $\mathrm{MCHC}$ & $\mathrm{g} / \mathrm{dL}$ & \\
\hline \multicolumn{4}{|c|}{ Parameters correlated to infections } \\
\hline White cell count & WBC & $\times 10^{9} / L$ & 9 \\
\hline $\begin{array}{l}\text { Lactate } \\
\text { dehydrogenase }\end{array}$ & $\mathrm{LDH}$ & $\mathrm{U} / \mathrm{L}$ & 280 \\
\hline $\mathrm{C}$ reactive protein & CRP & $\mathrm{mg} / \mathrm{dL}$ & 8 \\
\hline \multicolumn{4}{|c|}{ Iron correlated parameters } \\
\hline Iron & & $\mu g / d L$ & \\
\hline Ferritin & & $\mathrm{ng} / \mathrm{mL}$ & \\
\hline Transferrin saturation & TSAT & $\%$ & \\
\hline $\begin{array}{l}\text { Total iron binding } \\
\text { capacity }\end{array}$ & TIBC & $\mu \mathrm{g} / \mathrm{dL}$ & \\
\hline
\end{tabular}

and own definitions. Further differences occurred in the description and application of laboratory tests and units, names of the medications used and their categorisation in medication classes. Some of the medication entries were unclassified. The first step after data extraction and anonymisation was the data cleaning and standardisation of the entries.

For every centre, a list with the description of laboratory tests for blood parameters and applied units was generated. The same procedure was performed regarding the names of the medication, their units and the classes of the medications. Finally, all items in the categories blood parameters, and medication classes, were standardised. The generated list of the laboratory tests for blood parameters, and their descriptions including the units, was compared with the standardisation list. Differences in the writing of the descriptions were identified and a mapping list was defined for every centre. The same procedure was done for the units and additionally, it was also checked if differences in the units required a recalculation of the value to fit the standardised unit.

After that, mapping lists were defined and the entries in the database tables were standardised.

Table 1 shows the standardised blood parameters, the respective abbreviations and units and, if applicable, a threshold to define high values.

The description of the medications can be defined by the name of the substance or the product name. As with the laboratory values, the lists of every centre were compared with the standardised medication definitions.

\begin{tabular}{|c|c|c|}
\hline Hb-class & $\begin{array}{l}\text { Percentage of } \\
\text { values out of } \mathrm{Hb} \\
\text { range }(\%)\end{array}$ & $\begin{array}{l}\text { Number of values out of } \mathrm{Hb} \text { range } \\
\text { (120-day period and every } 14 \text { days } \\
\text { laboratory data) }\end{array}$ \\
\hline I & 0 to 34.9 & $0-2$ \\
\hline II & 35.0 to 69.9 & $3-5$ \\
\hline III & $\geq 70$ & $\geq 6$ \\
\hline
\end{tabular}

$\mathrm{Hb}$, haemoglobin

A ratio for medication per period was calculated by dividing the total number of medications per class by the number of periods in each Hb-class.

For the further calculations regarding the dose intensity of rHuEpo and darbepoetin alfa, $1 \mu \mathrm{g}$ of the latter was calculated conservatively as equivalent to $200 \mathrm{IU}$ rHuEpo. ${ }^{18}$ Moreover, in a Cochrane review no statistical differences in final $\mathrm{Hb}$ levels were reported between rHuEpo and the longer-acting darbepoetin because of different frequencies of administration. ${ }^{9}$

All dosages of the medication were normalised to the dosage per day and kilogram bodyweight.

\section{Proposed classification scheme}

The proposed scheme classifies a period of 120 days depending on the number of $\mathrm{Hb}$ values that exceed the predetermined range of $10-12 \mathrm{~g} / \mathrm{dL}$, as requested by Medicare ${ }^{20}$ provided that laboratory data are available every fortnight. The periods were individually determined for each patient. Starting with records from 2010 to ending in 2016, a computerised program identified any existing period of 120 days where the required data were available.

Three classes with comparable numbers of patients were projected. In the best case, in Hb-class I, there are up to two values out of the targeted $\mathrm{Hb}$ range in one 120-day period. Hb-class II includes three to five values out of range, and finally $\mathrm{Hb}$-class III comprises those with more than five values out of range. Table 2 shows the $\mathrm{Hb}$-classes with their respective definition.

\section{Statistical analysis}

To summarise data, individual patient data per period were used to calculate individual mean values for all parameters from table 1 . These means per period were then used as single data to calculate mean values for the description of Hb-classes. Each patient's individual minimum and maximum values were taken to calculate mean minimum and maximum values of the respective Hb-class. The non-parametric Skillings-Mack test was applied to determine differences between $\mathrm{Hb}$-classes in all variables from table 1 . The null hypothesis that the location parameter of the test variable is equal in all classes is rejected only if one median or distribution significantly differs from the others. This specific test was applied because the data were grouped and except for $\mathrm{Hb}$ and ESA the other data items may contain missing values. For ratios and percentages, Pearson's $\mathrm{X}^{2}$ test of homogeneity 


\begin{tabular}{lc}
$\begin{array}{l}\text { Table } 3 \\
\text { dialysis centres }(\mathrm{n}=3349)\end{array}$ & $64.4(15.9)$ \\
\hline Age years, mean (SD) & 55.0 \\
Male, \% & \\
Race, $\mathrm{n}(\%)$ & $1264(37.7)$ \\
African American & $226(6.7)$ \\
Asian & $24(0.7)$ \\
Native American & $1614(48.2)$ \\
Caucasian & $29(0.9)$ \\
Hispanic & $192(5.7)$ \\
Other/unknown &
\end{tabular}

ESRD, end-stage renal disease.

was used to test for differences between classes. The null hypothesis of homogeneity is rejected if there is a significant deviation between at least two sampling distributions. Significance level was set to $\alpha=0.05$ for two-sided tests. All statistical analyses were calculated with the statistical software package R Release 3.2.3 for Linux (http:/ / cran.r-project.org).

\section{RESULTS}

Patients in the participating centres were on average $64.4 \pm 15.9$ years old; $55.0 \%$ were men. Table 3 shows baseline characteristics of patients and figure 2 illustrates the age distribution of the sample.

The patients included in the analysis $(n=3349)$ did not differ from those who were excluded in terms of age structure. The proportion of men was higher in the included patients than in the excluded patients (55\% vs $51 \%)$. Racial differences cannot be evaluated because of missing information in the subset of the excluded patients.

From 3349 patients, 27068 periods of 120 days (8899 patient years) were available for the analysis. Table 4 shows the usage of erythropoietic agents in each class, parameters of red blood cells, parameters correlated to infections, iron correlated parameters and ratios of iron medication, transfusion and antibiotics.

The statistical analysis reveals significant differences between $\mathrm{Hb}$-classes in all of the examined parameters, except mean corpuscular volume and $\mathrm{C}$ reactive protein (CRP) high, with more critical values in the

\section{Distribution of Age}

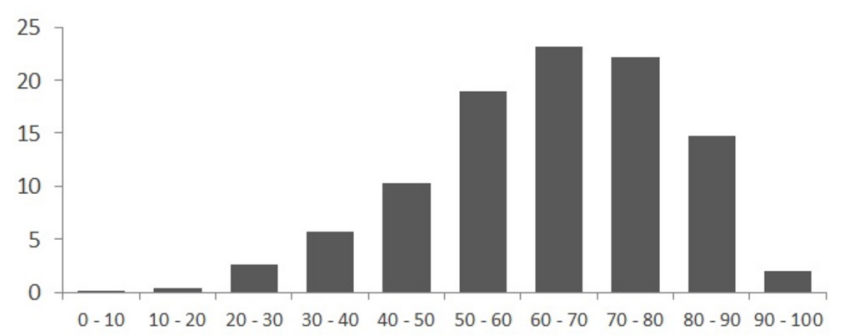

Figure 2 Age distribution of the 3349 patients with endstage renal disease in participating dialysis centres. higher classes. Darbepoetin alfa was used in $13 \%$ of the medication doses administered. There were no differences in the allocation to Hb-classes between those who received darbepoetin alfa and those who were treated with rHuEpo.

Figure 3 illustrates the average use of erythropoietic agents in each class and the respective percentage of $\mathrm{Hb}$ values above $12.0 \mathrm{mg} / \mathrm{dL}$ and below $10.0 \mathrm{mg} / \mathrm{dL}$.

\section{DISCUSSION}

Our goal was to classify the amount of $\mathrm{Hb}$ variability and fluctuations as major problems of $\mathrm{Hb}$ management in patients with ESRD and to offer a very simple and easily understandable classification system that facilitates to group patients in manageable classes for further consideration. Hence, the presented classification provides a pragmatic method to evaluate $\mathrm{Hb}$ trajectories in terms of exceeding or falling below the predefined $\mathrm{Hb}$ target values in predetermined periods for a single patient or a whole dialysis centre. The usage of a range from 1 to 3 is common in medical classification approaches and physicians are familiar with the interpretation of such classifications. The classification itself is neutral and without any implicit valuation. The application of the classification grades offers a clear description of an individual patient or a patient collective in terms of patients' responsiveness or performance of the respective anaemia management. They allow a valuable overview for long-term patients, and for comparing dialysis centres regarding their patient pool. A classification system like this, integrated into a disease management programme (DMP) for ESRD, as proposed by Rubin et $a l^{21}$ or into continuous quality improvement (CQI) as investigated by Nunes et $a l^{22}$ could improve and stabilise the quality of care provided to affected patients. Moreover, the classification can be integrated into a clinical decision support system. In the past, several approaches have been developed that take a further step and propose specific ESA dosing in individual patients. ${ }^{23}$ Despite promising results none of them has yet reached the status of a standard tool and further research is necessary to identify the best option. Our classification system can deliver valuable information on the performance of such a tool to optimise anaemia management.

We chose a period of time of 120 days mainly because this is within the range of the usually reported survival time of an erythrocyte and at least 3 months are considered to be a necessary time frame to evaluate the treatment success. $^{2325}$ However, red blood cell survival is reported to be reduced in patients with $\mathrm{CKD}$, thus contributing to anaemia problems. ${ }^{26}$ We suppose those differences in erythrocyte survival time are based on individual cases and in order to cover the entire possible life span, we applied a period of 120 days to all patient data. We also looked at other period lengths but 120 days turned out to provide the best discriminatory power. Shorter periods (eg, 40 days, 80 days) could be helpful for individual 
Table 4 Parameter for $\mathrm{Hb}$-classes I-III in 120day periods

\begin{tabular}{|c|c|c|c|c|c|c|}
\hline \multicolumn{7}{|c|}{ Hb-class } \\
\hline & \multicolumn{3}{|c|}{$\mathbf{I}$} & \multicolumn{2}{|l|}{ II } & III \\
\hline \multirow[t]{2}{*}{$\begin{array}{l}\text { Number of values out } c \\
\text { range }\end{array}$} & & $1-2$ & & $3-5$ & & $\geq 6$ \\
\hline & $\mathbf{n}$ & $(n=2573)$ & $\mathbf{n}$ & $(n=2312)$ & $\mathbf{n}$ & $(n=2334)$ \\
\hline Periods, n (\%) & & $11533(42.6)$ & & $6936(25.6)$ & & 8599 (31.8) \\
\hline EPO† max, m & & 310.6 & & 222.4 & & 301.9 \\
\hline \multicolumn{7}{|c|}{ Parameters correlated to red blood cells } \\
\hline $\mathrm{Hb}, \mathrm{m}(\mathrm{SD}) \ddagger$ & 93294 & $10.8(0.5)^{\star \star \star}$ & 71538 & $10.8(0.8)$ & 135878 & $10.4(1.0)$ \\
\hline $\mathrm{Hb}$ min, $\mathrm{m}$ & & 10.1 & & 6.2 & & 5.9 \\
\hline Hct, m (SD)‡ & 72463 & $33.5(1.4)^{\star \star *}$ & 56481 & $33.2(2.3)$ & 116922 & $32.1(3.0)$ \\
\hline $\mathrm{MCV}, \mathrm{m}(\mathrm{SD}) \ddagger$ & 45803 & $93.1(2.3)$ & 37057 & $93.3(2.5)$ & 82124 & $93.0(2.6)$ \\
\hline $\mathrm{MCH}, \mathrm{m}(\mathrm{SD}) \ddagger$ & & $30.7(0.5)^{\star * *}$ & & $30.6(0.6)$ & & $30.4(0.7)$ \\
\hline $\mathrm{MCHC}, \mathrm{m}(\mathrm{SD}) \ddagger$ & & $32.6(0.4)^{\star \star \star}$ & & $32.5(0.5)$ & & $32.4(0.6)$ \\
\hline \multicolumn{7}{|c|}{ Parameters correlated to infections } \\
\hline WBC, m (SD)‡ & 45234 & $7.2(0.7)^{\star \star \star}$ & 36473 & $7.3(1.0)$ & 81406 & $7.7(1.4)$ \\
\hline WBC high, $n(\%) \S$ & & $6822(15.1)^{\star \star \star}$ & & $6469(17.7)$ & & $19643(24.1)$ \\
\hline LDH high, $\mathrm{n}(\%) \S$ & 15001 & $496(3.3)^{\star \star \star}$ & 11412 & $631(5.5)$ & 16993 & $1472(8.7)$ \\
\hline Iron medication ratio|§ & 47824 & $4.15^{\star \star \star}$ & 39106 & 5.64 & 52106 & 6.06 \\
\hline Transfusion ratio $§$ & 54 & $0.0047^{\star \star \star}$ & 193 & 0.278 & 1539 & 0.179 \\
\hline Antibiotics ratioๆ§ & 9522 & $0.8256^{\star \star \star}$ & 9421 & 1.3583 & 15016 & 1.7462 \\
\hline
\end{tabular}

${ }^{*} p<0.05$

${ }^{* *} \mathrm{p}<0.01$

${ }^{* * *} \mathrm{p}<0.001$

†Erythropoietin (EPO), Units/day and kilogram body weight.

$\ddagger$ Skillings-Mack test.

$\S$ Pearson's $\chi^{2}$ test.

INumber of medication per period.

CRP, C reactive protein; $\mathrm{Hb}$, haemoglobin; Hct, haematocrit; $\mathrm{LDH}$, lactate dehydrogenase; $\mathrm{MCH}$, mean corpuscular haemoglobin; $\mathrm{MCHC}$, mean corpuscular haemoglobin concentration; MCV, mean corpuscular volume; $n$, number of data; N, number of patients; TIBC, total iron binding capacity; TSAT, transferrin saturation; WBC, white cell count.

analyses regarding single patients and could be used in anaemia management directly.

There are several reasons why time periods for patients may have to be assigned to a certain HB-class. One important reason is the presence or absence of infections. Patients with ESRD are at a high risk of getting an infection and, in the USA, infection is the second leading cause of death in those patients. ${ }^{27}$ The reasons for this increased risk of infection are manifold, ranging from disease-related factors to environmental and healthcare factors. ${ }^{28}$ Altogether the whole risk for infections is much greater than the sum of its single parts. At least partially, infection rates may represent the quality of healthcare.

Another reason for the assignment to a higher Hb-class with a larger number of $\mathrm{Hb}$ values out of range may be due to the missing application of a protocol for the anaemia management. Using an anaemia management protocol can result in a smaller demand for erythropoietic agents 
120 days period

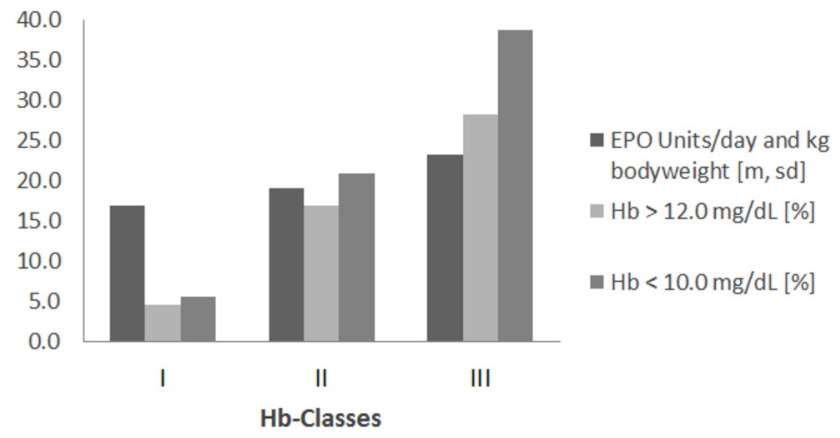

Figure 3 Erythropoietin (EPO) units/day and kilogram body weight, percentage of $\mathrm{Hb}$ values $>12.0 \mathrm{mg} / \mathrm{dL}$ and percentage of $\mathrm{Hb}$ values $<10.0 \mathrm{mg} / \mathrm{dL}$ in $\mathrm{Hb}$-classes I-III.

and an increase in the number of patients in the target $\mathrm{Hb}$ range. ${ }^{29}$ Furthermore, adherence to an anaemia management protocol leads to better results in reaching the target $\mathrm{Hb}$ range ${ }^{30}$ Regulation problems in anaemia management may arise if a protocol is not working properly, with regard to the specifics of a medication like EPO that has no immediate but a more long-term effect, while decisions regarding a patient are made in a short-term setting. Lastly, facility related factors also significantly influence the probability of achieving $\mathrm{Hb}$ targets. ${ }^{31}$

A frequently discussed problem in the application of $\mathrm{EPO}$ is the so-called $\mathrm{Hb}$ cycling, a cyclic fluctuation of $\mathrm{Hb}$ levels. ${ }^{10}$ In a study of Fishbane and Berns more than $90 \%$ of patients experienced this periodic rising and falling of $\mathrm{Hb}$ levels. ${ }^{10} \mathrm{Hb}$ cycling seems to be closely associated to frequent changes in EPO doses, ${ }^{10}$ and thus directly related to anaemia management and respective protocols. On the other hand, Gupta and David showed that the variability of $\mathrm{Hb}$ is not entirely explained by the administration of ESA; physiological factors like age seem to play an important role. ${ }^{32}$ In elderly patients with ESRD $(>60$ years) the $\mathrm{Hb}$ variability was similar to those in healthy elders, and patients on dialysis who do not require ESA also show $\mathrm{Hb}$ variability. ${ }^{32}$ Hence, $\mathrm{Hb}$ variability in dialysis patients is not exclusively caused by the administration of EPO, but also a physiological process connected to ageing and disease.

As mentioned above, infections are a serious problem in the anaemia management of patients with ESRD on dialysis. Within the present data, we only have laboratory parameters that can be used as indicators for infections. CRP was not measured very often. Alternatively, WBC and $\mathrm{LDH}$ values can be used as indicators for infections. The proportion of high WBC values varies between $15.1 \%$ in Hb-class I and $24.1 \%$ in Hb-class III, a similar tendency as the high values of $\mathrm{LDH}$ which amount to $3.3 \%$ in the lowest $\mathrm{Hb}$-class versus $8.1 \%$ in the highest. These results underline the assumption that infections may partly be a reason for the assignment to a higher Hb-class. Closer analyses regarding these parameters are a task for further research.

\section{Clinical application of the classification system}

The benefit of an application of the proposed classification system in anaemia management is, at first, the assessment and documentation of the status quo. A second step could be, for instance, a critical review of the application of the anaemia protocol or the protocol itself in order to move patients from higher $\mathrm{Hb}$-classes to lower Hb-classes. Existing protocols for anaemia management can be compared regarding their outcome in a simplified manner and any changes can be reviewed. For the practical application of the classification system an implementation into software is recommendable and easily realisable due to its convenience. Subsequently patients can be at any time assigned to a Hb-class by means of their patient record. It is understood that Hb-class III patients need a more closer look than Hb-class I patients.

The application of a DMP or an anaemia protocol may both help to reduce costs. ${ }^{29}{ }^{33}$ Provided that both the DMP and the anaemia protocol work to keep the assignment to Hb-classes II and III low in favour of Hb-class I, the savings can be easily expressed in a reduced use of EPO. The mean difference between Hb-class III and Hb-class I in our sample are 6.4 units / day and kilogram body weight in a 120-day period.

There exists a plethora of guidelines for anaemia management, so we have focused here on those which apply in an international or more global context. The KDIGO group provides highly developed guidelines for anaemia management in patients with $\mathrm{CKD}^{14}$ which have already been adapted for the European Region. ${ }^{34}$ So what is missing in anaemia management is not information on how to proceed, but on how to evaluate the results.

\section{Strengths and limitations}

With more than 27 000, 120-day periods (8899 patient years) analysed, this research is based on a big data volume, strengthening the conclusions to be drawn. Furthermore, according to the comprehensive data source and large data volume, the generalisability, with regard to other patients with ESRD on haemodialysis and being treated with ESAs, is acceptable. With its simplicity, the proposed classification scheme can be applied easily and facilitates comparisons in any direction.

One limitation is the large number of data sets that were omitted because of missing data. For $40 \%$ of haemodialysis patients in the database no information on the use of ESAs was provided. Regarding those data bases, we assume that those records were randomly missing and have little influence on the development of the classification scheme and results. On the other hand, Khan et al report that frequent $\mathrm{Hb}$ measurements and timely ESA dose adjustments is associated with lower $\mathrm{Hb}$ variation ${ }^{35}$ which would mean that our data represent-at least regarding continuous measurement of $\mathrm{Hb}-\mathrm{a}$ positive selection. 


\section{CONCLUSION}

Our classification system offers an easily applicable tool to measure the quality of anaemia management in patients with ESRD on haemodialysis. It facilitates the comparability between dialysis centres as well as between single patients. It is based on a broad data source and classes are recognisably differentiated in all important key variables. Integrated in a DMP or CQI, the classification delivers an instant appraisal without complex statistical or mathematical processing. The straightforward evaluation of the golden rule of anaemia management, to keep $\mathrm{Hb}$ levels constantly within the target range, is readily available.

Contributors TK had the idea and performed the statistical analysis. US was responsible for the data extraction and anonymisation. TK and US conducted the data management. TK and DK did the literature research. DK drafted the manuscript and generated the figures and tables. TK and US revised the manuscript drafts.

\section{Competing interests None declared.}

Ethics approval As this study is based on an anonymised secondary data analysis, ethics approval is not required.

Provenance and peer review Not commissioned; externally peer reviewed.

Data sharing statement Data are available from TK (kesztyus@hs-ulm.de) on reasonable request.

Open Access This is an Open Access article distributed in accordance with the Creative Commons Attribution Non Commercial (CC BY-NC 4.0) license, which permits others to distribute, remix, adapt, build upon this work non-commercially, and license their derivative works on different terms, provided the original work is properly cited and the use is non-commercial. See: http://creativecommons.org/ licenses/by-nc/4.0/

(c) Article author(s) (or their employer(s) unless otherwise stated in the text of the article) 2017. All rights reserved. No commercial use is permitted unless otherwise expressly granted.

\section{REFERENCES}

1. Perico N, Remuzzi G. Chronic kidney disease: a research and public health priority. Nephrol Dial Transplant 2012;27(Suppl 3):iii19-26.

2. Centers for Disease Control and Prevention. Chronic Kidney Disease (CKD) surveillance project. 2016 https://nccd.cdc.gov/ckd/ (accessed 4 Jul 2016).

3. Saran R, Li Y, Robinson B, et al. Chapter 1 : incidence, prevalence, patient characteristics, and treatment modalities. Am J Kidney Dis 2015;66:S93-110.

4. Brück K, Stel VS, Gambaro G, et al. CKD prevalence varies across the European General Population. J Am Soc Nephrol 2016;27:2135-47.

5. Zoccali C, Kramer A, Jager KJ. Chronic kidney disease and endstage renal disease-a review produced to contribute to the report 'the status of health in the European union: towards a healthier Europe'. NDT Plus 2010;3:213-24.

6. Kramer HJ, Saranathan A, Luke A, et al. Increasing body mass index and obesity in the incident ESRD population. J Am Soc Nephrol 2006;17:1453-9.

7. Eschbach JW, Abdulhadi MH, Browne JK, et al. Recombinant human erythropoietin in anemic patients with end-stage renal disease. results of a phase III multicenter clinical trial. Ann Intern Med 1989;111:992-1000.

8. Coronado Daza J, Martí-Carvajal AJ, Ariza García A, et al. Early versus delayed erythropoietin for the anaemia of end-stage kidney disease. Cochrane Database Syst Rev 2015 12:CD011122.

9. Hahn D, Cody J, Hodson E. Frequency of administration of erythropoiesis-stimulating agents for the anaemia of end-stage kidney disease in dialysis patients. Cochrane Database Syst Rev 2014;5:CD003895.

10. Fishbane S, Berns JS. Evidence and implications of haemoglobin cycling in anaemia management. Nephrol Dial Transplant 2007;22:2129-32.
11. Yang W, Israni RK, Brunelli SM, et al. Hemoglobin variability and mortality in ESRD. J Am Soc Nephrol 2007;18:3164-70.

12. KDOQI. KDOQI clinical practice guideline and clinical practice recommendations for anemia in chronic kidney disease: 2007 update of hemoglobin target. Am J Kidney Dis 2007;50:479-512.

13. Strippoli GF, Navaneethan SD, Craig JC. Haemoglobin and haematocrit targets for the anaemia of chronic kidney disease. Cochrane Database Syst Rev 2006;4:CD003967.

14. KDIGO. Clinical practice guideline for anemia in chronic kidney disease. Kidney Int Suppl 2012;2:279-335.

15. Arbor Research Collaborative for Health. DOPPS Practice Monitor (Internet). Reporting contemporary trends in U.S. dialysis practice. 2016 http://www.dopps.org/dpm/ (accessed 04 Jul 2016).

16. Barbieri C, Molina M, Ponce P, et al. An international observational study suggests that artificial intelligence for clinical decision support optimizes anemia management in hemodialysis patients. Kidney Int 2016;90:422-9.

17. Nafar M, Samavat S, Khoshdel A, et al. Anemia evaluation and erythropoietin dose requirement among hemodialysis patients: a multicenter study. Iran J Kidney Dis 2017;11:56-65.

18. Scott SD. Dose conversion from recombinant human erythropoietin to darbepoetin alfa: recommendations from clinical studies. Pharmacotherapy 2002;22:160S-5.

19. Amgen Switzerland AG. Drug information Aranesp. Switzerland: Amgen Switzerland AG, 2016. https://compendium.ch/ FrmMainMonographie.aspx?ID=c1ce189f-180f-4b20-a6d2bce3f6d725d7\&lang=de\&MonType=fi (accessed 04 Jul 2016).

20. UnitedHealthcare. Erythropoieting Stimulating Agent (ESA) policy guideline. 2016:1-11 https://www.unitedhealthcareonline.com/ ccmcontent/ProviderlI/UHC/en-US/Main Menu/Tools \& Resources/ Policies and Protocols/Medicare Advantage Policy Guidelines/ Erythropoietin_Stimulating_Agent.pdf (accessed 04 Jul 2016).

21. Rubin RJ, Shapiro JR, Hines SJ, et al. Disease management: what have we learned so far? Blood Purif 2001;19:353-60.

22. Nunes JW, Seagull FJ, Rao P, et al. Continuous quality improvement in nephrology: a systematic review. BMC Nephrol 2016;17:190.

23. Barbieri C, Bolzoni E, Mari F, et al. Performance of a predictive model for long-Term hemoglobin response to darbepoetin and iron administration in a large cohort of hemodialysis patients. PLoS One 2016;11:1-18.

24. Brier ME, Gaweda AE. Artificial intelligence for optimal anemia management in end-stage renal disease. Kidney Int 2016;90:259-61.

25. Franco RS. Measurement of red cell lifespan and aging. Transfus Med Hemother 2012;39:302-7.

26 Vos FE, Schollum JB, Coulter CV, et al. Red blood cell survival in long-term dialysis patients. Am J Kidney Dis 2011;58:591-8.

27. Sarnak MJ, Jaber BL. Mortality caused by sepsis in patients with end-stage renal disease compared with the general population. Kidney Int 2000;58:1758-64.

28. Collier S, Davenport A. Reducing the risk of infection in end-stage kidney failure patients treated by dialysis. Nephrol Dial Transplant 2014;29:2158-61.

29. Charlesworth EC, Richardson RM, Battistella M. Cost savings using a protocol approach to manage anemia in a hemodialysis unit. $A m \mathrm{~J}$ Nephrol 2014;39:509-14.

30. Chan K, Moran J, Hlatky M, et al. Protocol adherence and the ability to achieve target haemoglobin levels in haemodialysis patients. Nephrol Dial Transplant 2009;24:1956-62.

31. Chan KE, Lafayette RA, Whittemore AS, et al. Facility factors dominate the ability to achieve target haemoglobin levels in haemodialysis patients. Nephrol Dial Transplant 2008;23:2948-56.

32. Gupta AK, David W. Does erythropoietin cause hemoglobin variability--is it 'normal'? PLoS One 2014;9:e92890.

33. Gandjour A, Tschulena U, Steppan S, et al. A simulation model to estimate cost-offsets for a disease-management program for chronic kidney disease. Expert Rev Pharmacoecon Outcomes Res 2015;15:341-7.

34. Locatelli F, Bárány P, Covic A, et al. Kidney disease: improving global outcomes guidelines on anaemia management in chronic kidney disease: a European renal best practice position statement. Nephrol Dial Transplant 2013;28:1346-59.

35. Khan I, Krishnan M, Kothawala A, et al. Association of dialysis facility-level hemoglobin measurement and erythropoiesisstimulating agent dose adjustment frequencies with dialysis facilitylevel hemoglobin variation: a retrospective analysis. BMC Nephrol 2011;12:22. 